\title{
Compendium of Total Ionizing Dose and Displacement Damage for Candidate Spacecraft Electronics for NASA
}

\author{
Donna J. Cochran ${ }^{1}$, Alvin J. Boutte ${ }^{2}$, Dakai Chen ${ }^{2}$, Jonathan A. Pellish ${ }^{2}$, Raymond L. Ladbury ${ }^{2}$, Megan C. Casey ${ }^{2}$, Michael J. \\ Campola $^{2}$, Edward P. Wilcox ${ }^{1}$, Martha V. O’Bryan ${ }^{1}$, Kenneth A. LaBel ${ }^{2}$, Jean-Marie Lauenstein ${ }^{2}$, \\ David A. Batchelor ${ }^{2}$, and Timothy R. Oldham ${ }^{3}$ \\ 1. MEI Technologies, Inc., Seabrook, MD 20706 USA \\ 2. NASA Goddard Space Flight Center (GSFC), Code 561.4, Greenbelt, MD 20771 USA \\ 3. Dell Perot Systems Inc., Fairfax, VA 22031 USA
}

Abstract-- Vulnerability of a variety of candidate spacecraft electronics to total ionizing dose and displacement damage is studied. Devices tested include optoelectronics, digital, analog, linear, and hybrid devices.

Index Terms- Displacement Damage, Optoelectronics, Proton Damage, Single Event Effects, and Total Ionizing Dose.

\section{INTRODUCTION}

NASA spacecraft are subjected to a harsh space environment that includes exposure to various types of ionizing radiation. Long-term exposure to radiation has been known to affect the function of the spacecraft electronics. As a result, flight parts must be tolerant to radiation-induced Total Ionizing Dose (TID) and displacement damage (DD) effects or be mitigated by shielding or other methods to reduce TID and DD effects. Hence, the effects of TID and DD need to be evaluated by test in order to determine risk to spaceflight applications.

This work was supported in part by the NASA Electronic Parts and Packaging Program (NEPP), NASA Flight Projects, and the Defense Threat Reduction Agency (DTRA) under IACRO\# 11-4395I.

Donna J. Cochran is with MEI Technologies Inc., work performed for NASA Goddard Space Flight Center, Code 561.4, Greenbelt, MD 20771 (USA), phone: 301-286-8258, email: Donna.j.Cochran@nasa.gov

Alvin J. Boutte, NASA/GSFC, Code 561.4, Greenbelt, MD 20771 (USA), phone: 301-286-2128, email: Alvn.j.Boutte@nasa.gov.

Dakai Chen, NASA/GSFC, Code 561.4, Greenbelt, MD 20771 (USA), phone: 301-286-8595, email: Dakai.Chen-1@@nasa.gov.

Jonathan A. Pellish, NASA/GSFC, Code 561.4, Greenbelt, MD 20771

(USA), phone: 301-286-8046, email: Jonathan,a.Pellish@nasa.gov.

Raymond L. Ladbury, NASA/GSFC, Code 561.4, Greenbelt, MD 20771

(USA), phone: 301-286-1030, email: Raymond.1.Ladbury@nasa.gov.

Megan C. Casey, NASA/GSFC, Code 561.4, Greenbelt, MD 20771 (USA), phone: 301-286-1151, email: Megan.c.Casey@nasa.gov.

Michael J. Campola, NASA/GSFC, Code 561.4, Greenbelt, MD 20771 (USA), phone: 301-286- 5427, email: Michael.j.Campola@nasa.gov.

Edward P. Wilcox is with MEI Technologies Inc., work performed for NASA Goddard Space Flight Center, Code 561.4, Greenbelt, MD 20771 (USA), phone: 301-286-5292, email: Ted.Wilcox@nasa.gov.

David A. Batchelor, NASA/GSFC, Code 561.4, Greenbelt, MD 20771 (USA), phone: 301-286-2988, email: David.a.Batchelor@@nasa.gov Jean-Marie Lauenstein, NASA/GSFC, Code 561.4, Greenbelt, MD 20771 (USA), phone: 301-286-5587, email: jean.m.lauenstein@nasa.gov.

Timothy R. Oldham, Dell Perot Systems Government Services, Inc., work performed for NASA Goddard Space Flight Center, Code 561.4, Greenbelt, MD 20771 (USA), phone: 301-286-5489, email: Timothy.r.Oldham@nasa.gov.

Martha V. O'Bryan is with MEI Technologies Inc., work performed for NASA Goddard Space Flight Center, Code 561.4, Greenbelt, MD 20771 (USA), phone: 301-286-1312, email: Martha.v.Obryan@nasa.gov.

Kenneth A. LaBel, NASA/GSFC, Code 561.4, Greenbelt, MD 20771 (USA), phone: 301-286-9936, email: Kenneth.a.LaBel@nasa.gov.
The test results presented here were gathered to establish the sensitivity of candidate spacecraft electronics to TID and/or DD damage. Proton-induced degradation, dominant for most NASA missions, is a mix of ionizing (TID) and non-ionizing damage. The non-ionizing damage is commonly referred to as displacement damage (DD). For similar results on single event effects (SEE), a companion paper has also been submitted to the 2012 IEEE NSREC Radiation Effects Data Workshop entitled: "Compendium of Single Event Effects for Candidate Spacecraft Electronics for NASA" by M. O'Bryan, et al. [1]

\section{Test Techniques And Setup}

\section{A. Test Methods - TID}

TID testing was performed using a ${ }^{60} \mathrm{Co}$ source. Dose rates used for testing were between 0.05 and $18 \mathrm{rad}(\mathrm{Si}) / \mathrm{s}$.

\section{B. Test Methods - Proton}

Proton DD/TID tests were performed at the University of California at Davis (UCD) Crocker Nuclear Laboratory (CNL) using a 76" cyclotron (maximum energy of $63 \mathrm{MeV}$ ). Table I lists the proton damage test facilities and energies used on the devices.

TABLE I: PROTON TEST FACILITIES

\begin{tabular}{|c|c|}
\hline Facility & $\begin{array}{c}\text { Incident } \\
\text { Proton Energy, (MeV) }\end{array}$ \\
\hline $\begin{array}{c}\text { University of California at Davis (UCD) } \\
\text { Crocker Nuclear Laboratory (CNL) }\end{array}$ & $6.5-63$ \\
\hline
\end{tabular}

\section{Test Methods-Electron}

Unless otherwise noted, all tests were performed at room temperature and with nominal power supply voltages.

\section{Test Results Overview}

Abbreviations for principal investigators (PIs) are listed in Table II. Abbreviations and conventions are listed in Table III. Summary of TID and DD test results are listed in Table IV. 
TABLE II

LIST OF PRINCIPAL INVESTIGATORS

\begin{tabular}{|c|c|}
\hline Abbreviation & Principal Investigator (PI) \\
\hline $\mathrm{DB}$ & David Batchelor \\
\hline $\mathrm{AB}$ & Alvin Boutte \\
\hline $\mathrm{MiC}$ & Michael Campola \\
\hline $\mathrm{MeC}$ & Megan Casey \\
\hline $\mathrm{DC}$ & Dakai Chen \\
\hline $\mathrm{RL}$ & Raymond Ladbury \\
\hline JML & Jean-Marie Lauenstein \\
\hline $\mathrm{TO}$ & Timothy Oldham \\
\hline JP & Jonathan Pellish \\
\hline $\mathrm{EW}$ & Edward (Ted) Wilcox \\
\hline
\end{tabular}

TABLE III

ABBREVIATIONS AND CONVENTIONS

\begin{tabular}{|c|c|}
\hline 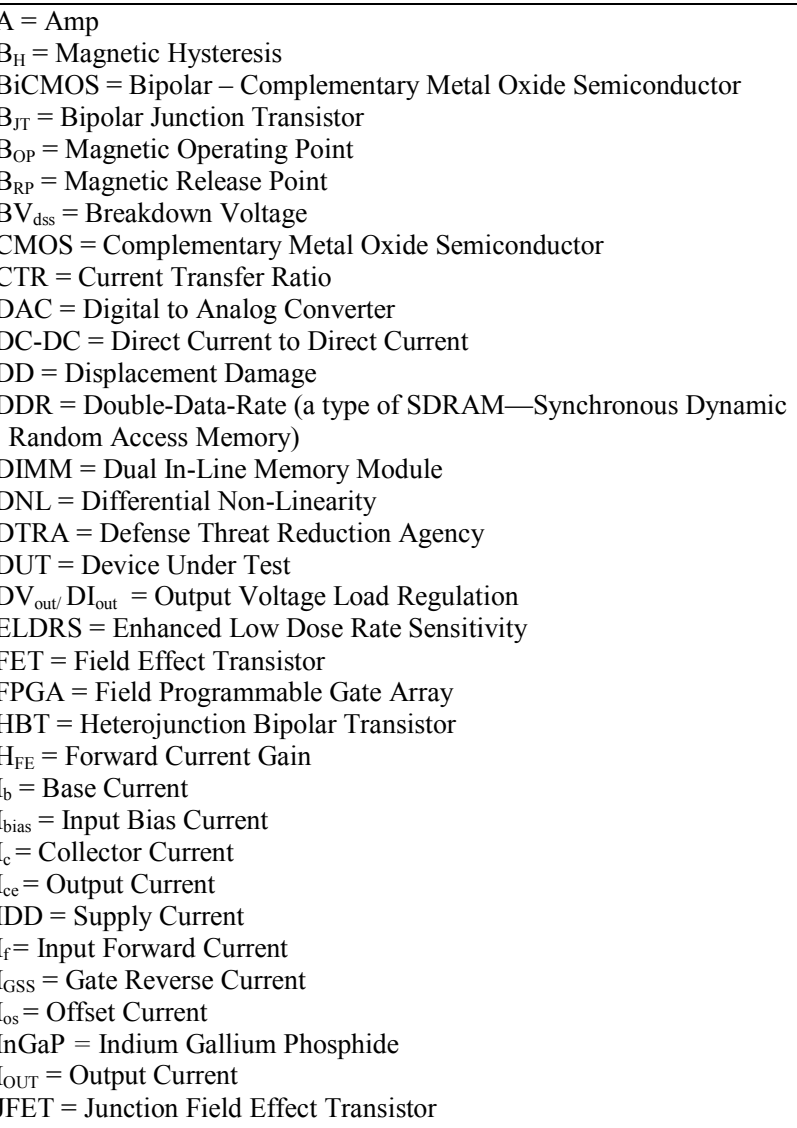 & 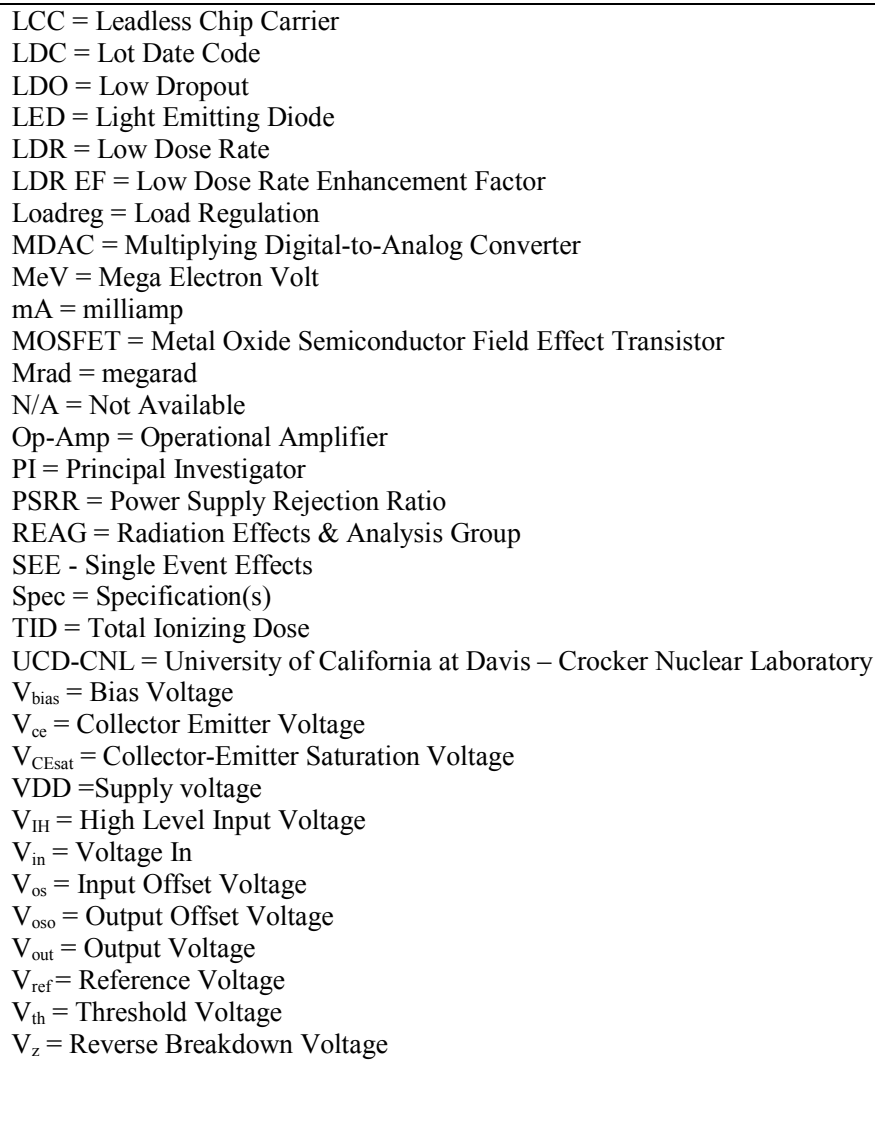 \\
\hline
\end{tabular}




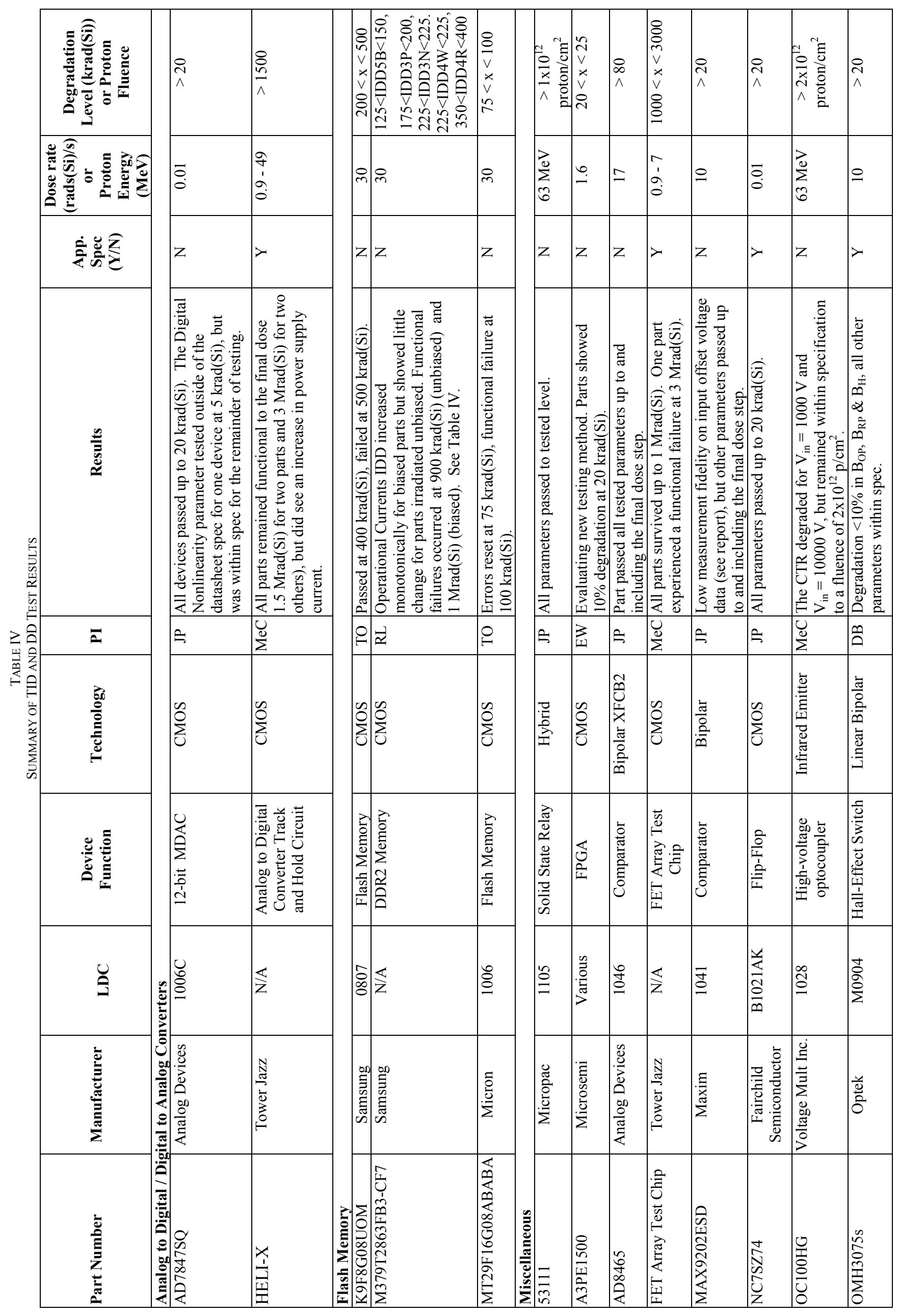




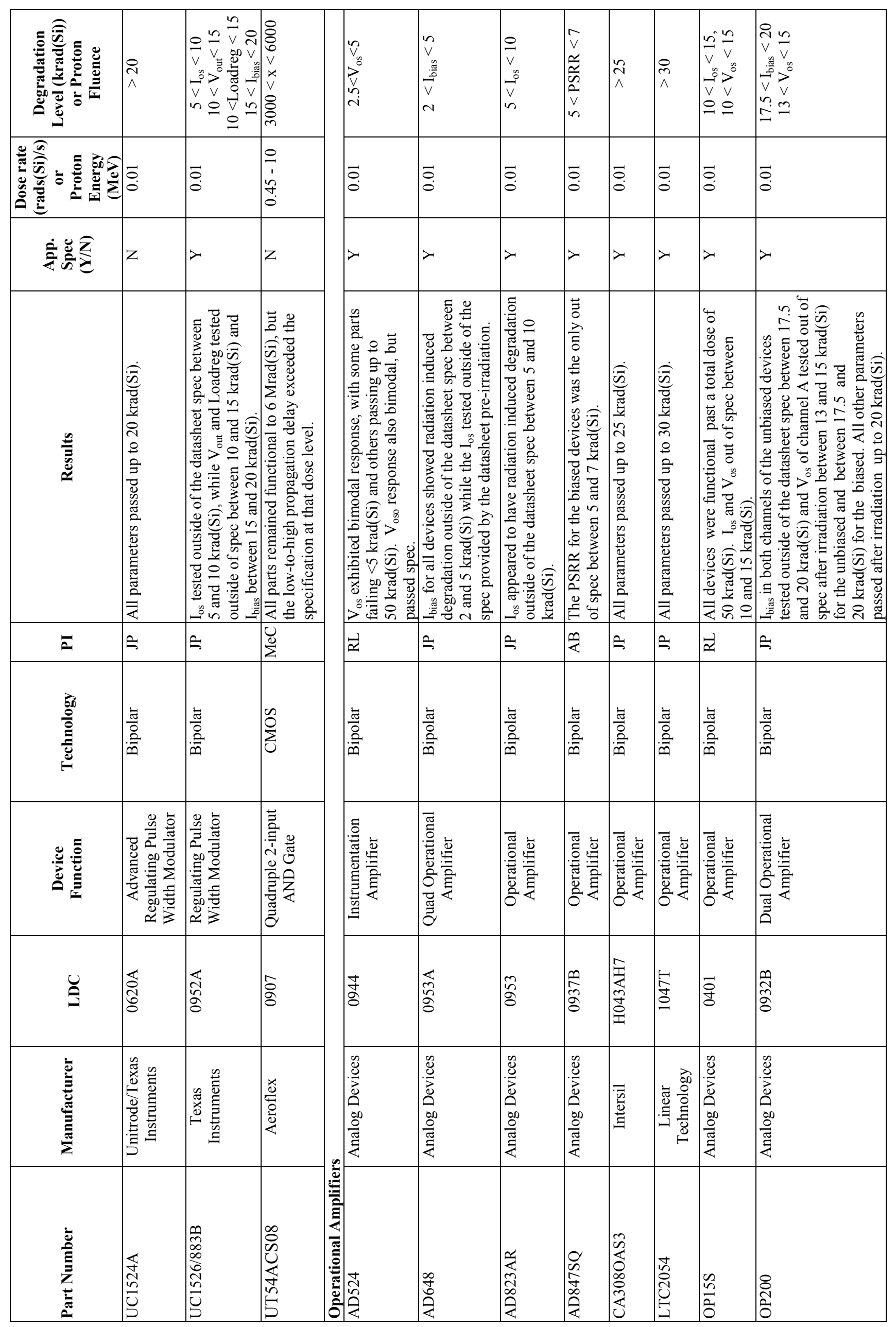




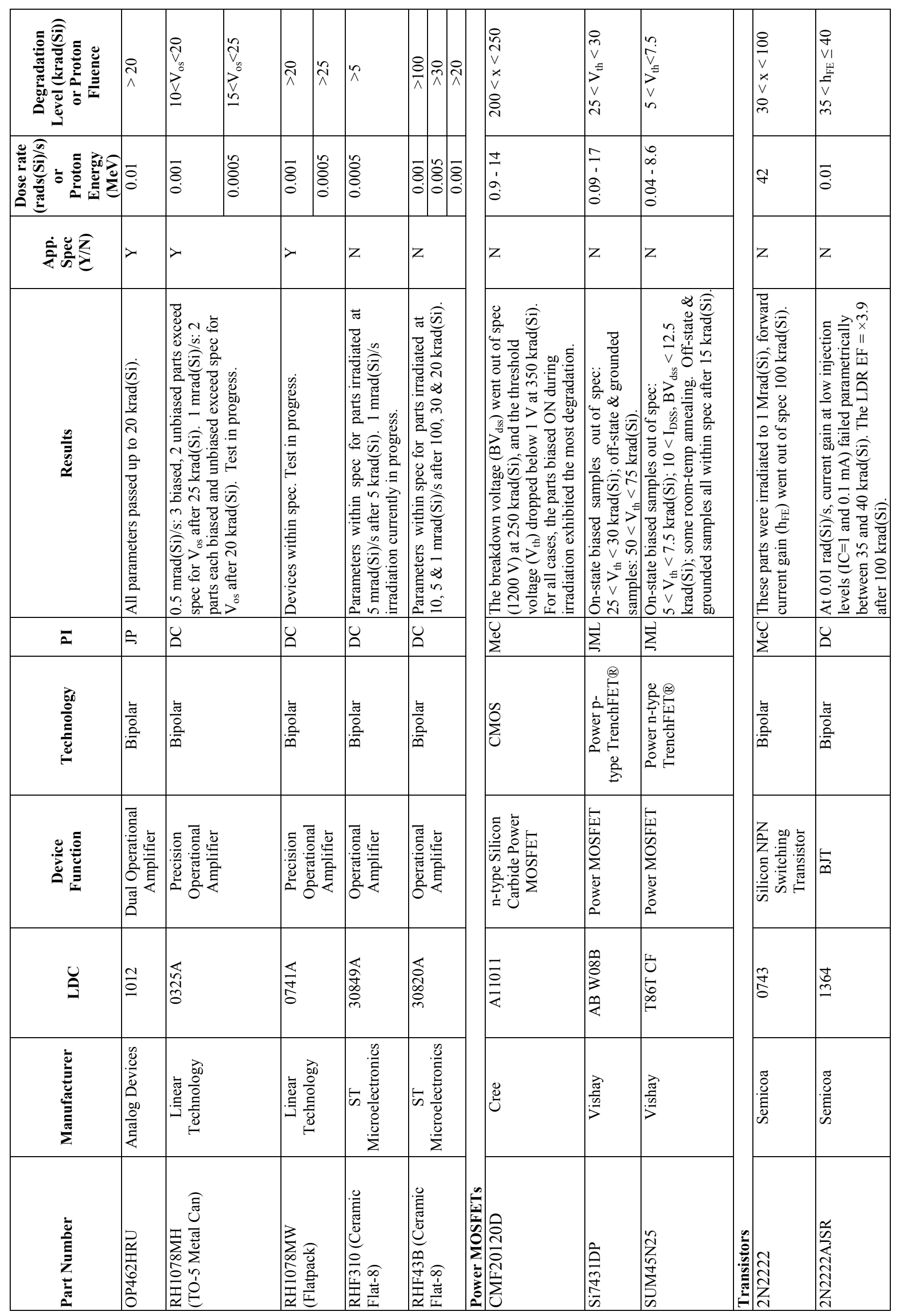




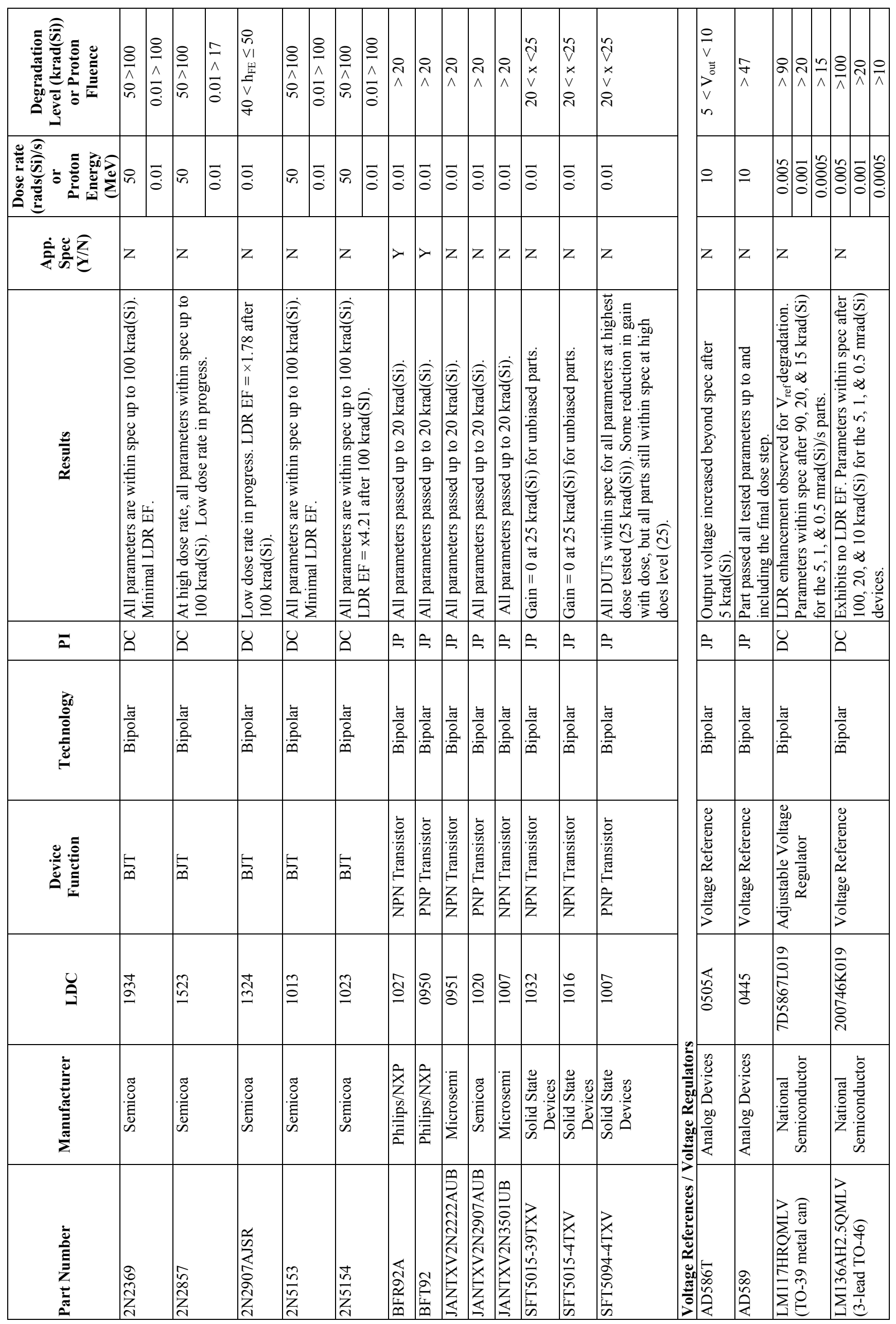




\begin{tabular}{|c|c|c|c|c|c|c|c|c|c|c|c|c|c|c|c|c|c|c|c|}
\hline 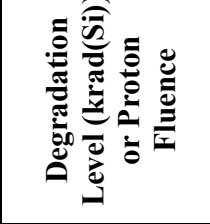 & $\begin{array}{l}\infty \\
\infty \\
\wedge\end{array}$ & $\stackrel{\sim}{\wedge} \stackrel{\sim}{\wedge}$ & 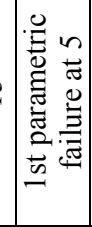 & $\underset{\wedge}{8}$ & $\stackrel{n}{\wedge}$ & 18 & 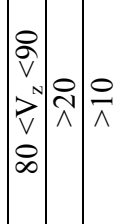 & 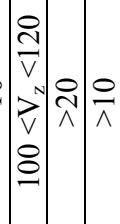 & 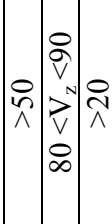 & 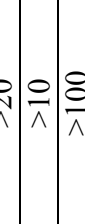 & & 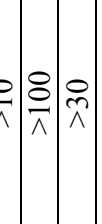 & 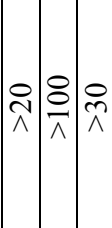 & 에 & 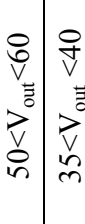 & 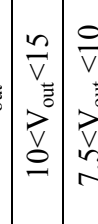 & 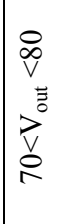 & $\stackrel{ }{\wedge} \frac{5}{1}$ & \\
\hline 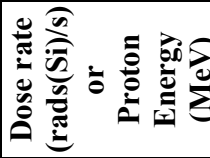 & 年 & $\mid$\begin{tabular}{l|l}
$\overrightarrow{8}$ & \multicolumn{2}{c}{} \\
\hdashline & 0 \\
$\dot{0}$ & 0 \\
0
\end{tabular} & in & 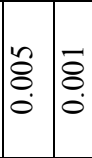 & $\mid$ & $\ddot{0}$ & 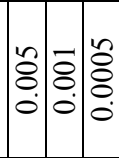 & 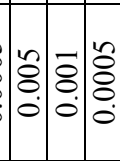 & 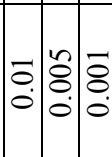 & : & 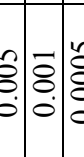 & 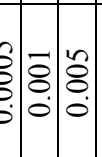 & 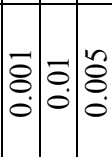 & : & 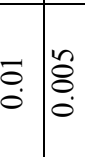 & 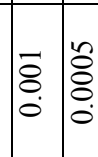 & 告 & 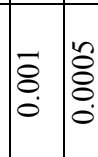 & \\
\hline 家离衣 & z & & z & $z$ & & $\lambda$ & z & z & z & & Z & z & $\mathrm{z}$ & & z & & Z & & \\
\hline 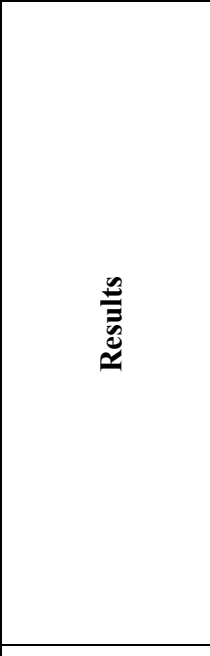 & 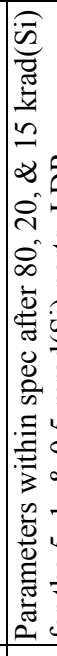 & 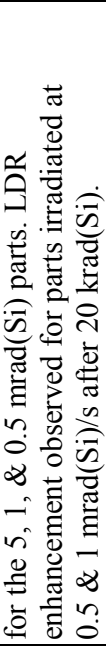 & 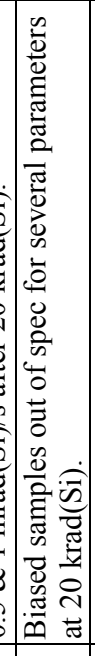 & 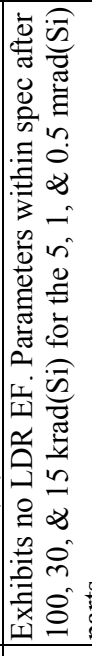 & & 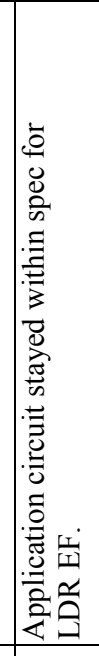 & 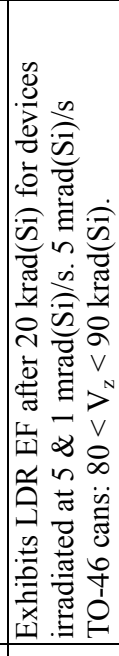 & 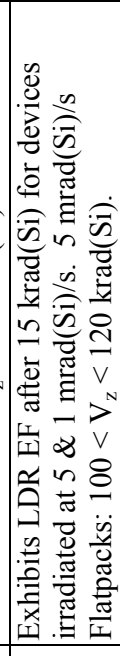 & 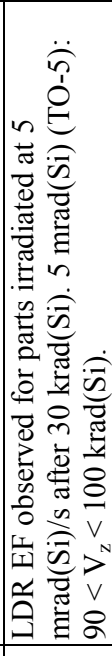 & & 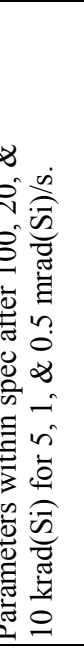 & 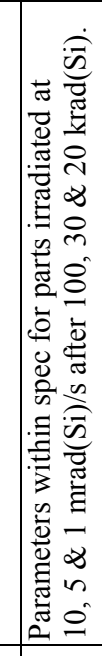 & 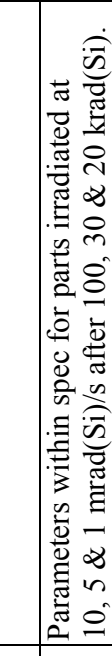 & & 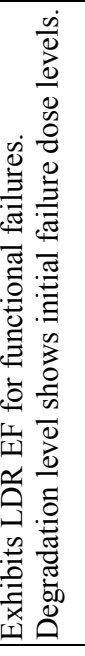 & & & 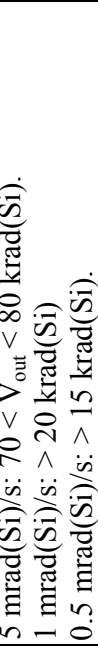 & \\
\hline $\bar{a}$ & Ø̊ & & $\Leftrightarrow$ & Ø̊ & & $\stackrel{\sum}{\Sigma}$ & ○ & Ø̊ & Ø̊ & Ø & صِ & Ø & Ø̊ & & Øִ & & ๑ & & \\
\hline 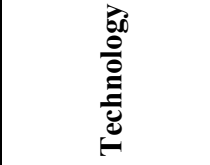 & 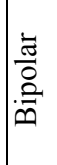 & & $\sum_{0}^{\infty}$ & 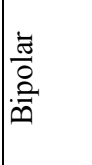 & & 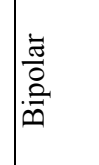 & 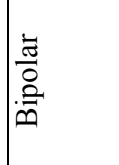 & 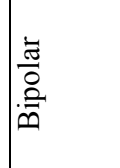 & 咅 & & 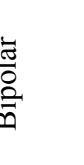 & 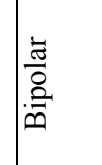 & 咅 & & 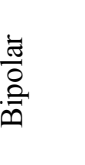 & & 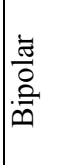 & & \\
\hline 递泀 & $\begin{array}{l}0 \\
0 \\
\underline{5} \\
0 \\
0 \\
0 \\
0 \\
: \\
0 \\
0 \\
0 \\
0\end{array}$ & 节 & 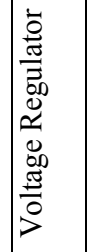 & 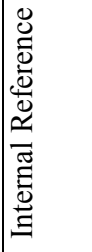 & & 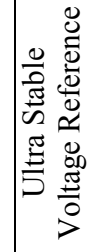 & 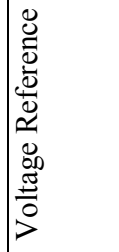 & 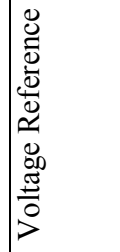 & 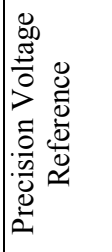 & & 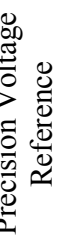 & 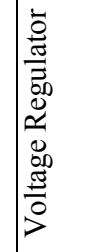 & 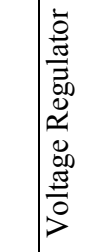 & & 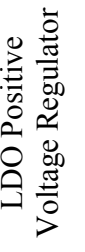 & & $\begin{array}{l}0 \\
0 \\
0 \\
0 \\
0 \\
0 \\
0 \\
0 \\
3 \\
-1 \\
1\end{array}$ & & \\
\hline בِ & 象 & & 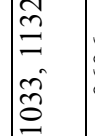 & 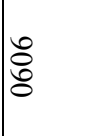 & & $\overrightarrow{\widetilde{\infty}}$ & 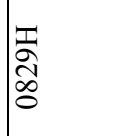 & 造 & $\begin{array}{l}\frac{1}{\infty} \\
\infty \\
\stackrel{\infty}{a}\end{array}$ & & $\begin{array}{c}4 \\
\vdots \\
0 \\
\end{array}$ & $\begin{array}{l}\varangle \\
\infty \\
0 \\
\infty \\
0 \\
\infty\end{array}$ & 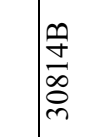 & & 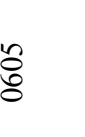 & & î & & \\
\hline 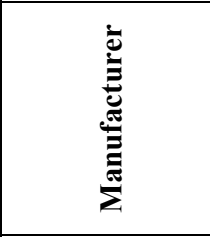 & 芯 & 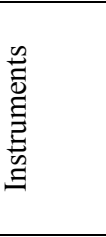 & 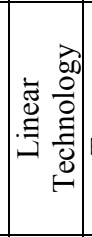 & 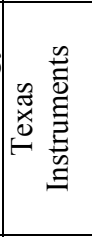 & & 离 & 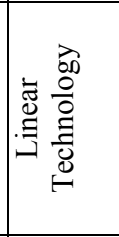 & 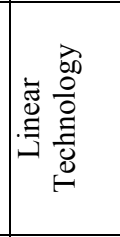 & 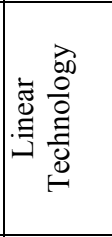 & & 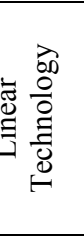 & 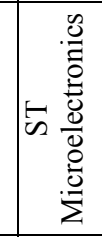 & 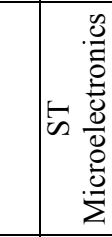 & & 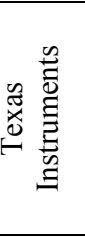 & & 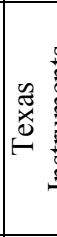 & & \\
\hline 离 & 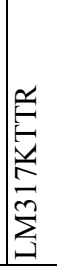 & & $\mid \begin{array}{l}\hat{\alpha} \\
\infty \\
\overrightarrow{0} \\
\vdots \\
⿶ \\
\end{array}$ & 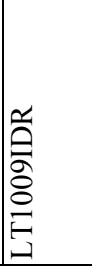 & & 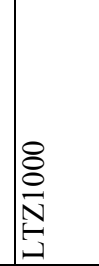 & 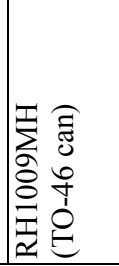 & 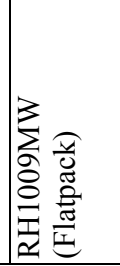 & 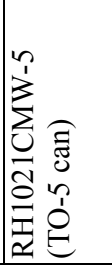 & & 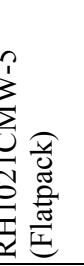 & 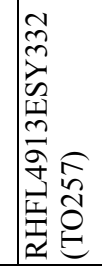 & 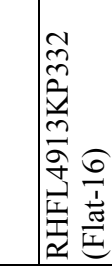 & 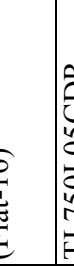 & 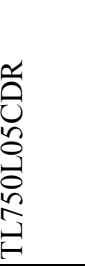 & & 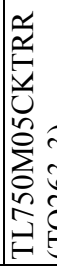 & & \\
\hline
\end{tabular}




\section{Test Results And Discussion}

As in our past workshop compendia of GSFC test results, each DUT has a detailed test report available online at http://radhome.gsfc.nasa.gov [3] describing in further detail, test method, TID conditions/parameters, test results, and graphs of data.

\section{A. CMF20120D/n-channel enhancement mode Silicon Carbide MOSFET/CREE}

The CMF20120D is a n-channel enhancement mode Silicon Carbide MOSFET manufactured by CREE using their Z-FET technology. The samples in this test were surface-mounted on copper boards having pins designed to plug into wire wrap sockets. The parts were irradiated using a ${ }^{60} \mathrm{Co}$ source, at varying dose rates of $500-1000$ $\mathrm{rad}(\mathrm{Si}) / \mathrm{min}$ during the day and $5-25 \mathrm{rad}(\mathrm{Si}) / \mathrm{min}$ overnight, to a total dose of $400 \mathrm{krad}(\mathrm{Si})$. The parts were tested until the threshold voltage dropped below $1 \mathrm{~V}$ (there is no minimum threshold voltage specified for these parts). On the other hand, breakdown voltage deteriorated beyond the minimum $1200 \mathrm{~V}$ specification between 200 and 250 $\operatorname{krad}(\mathrm{Si})$. After that point, the MOSFETs underwent a one-week room-temperature anneal under bias, with measurements at 24 hours post-anneal, and following the full 168 hour anneal. Parts were then irradiated for an additional $200 \mathrm{krad}(\mathrm{Si})$. They were then subjected to a 168-hour anneal at $100{ }^{\circ} \mathrm{C}$, with measurements only after the full time period. A total of ten MOSFETs were used for this test, nine of which were biased either in an onstate, off-state, or grounded state, with the remaining device used as a control. Specifically, the on-state bias conditions were $20 \mathrm{~V}$ on the gate and grounded source and drain; the off-state bias conditions were grounded gate and source and $900 \mathrm{~V}$ on the drain; and the grounded bias conditions shorted all pins to ground.

Fig. 1 shows the average threshold voltage for each bias condition and the control as a function of dose. Likewise, Fig. 2 plots the breakdown voltage as a function of dose. All averaged parameters stayed within specification to 400 $\operatorname{krad}(\mathrm{Si})$, except the breakdown voltage. After the week long high temperature anneal, all parameters returned to their pre-rad values.

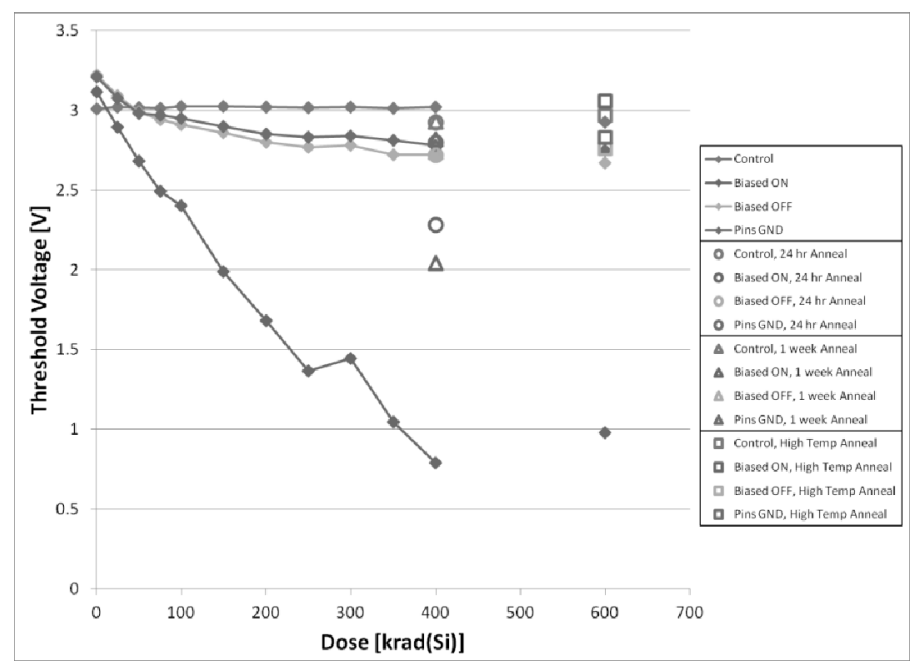

Fig. 1. The average threshold voltage for the CMF20120D as a function of dose.

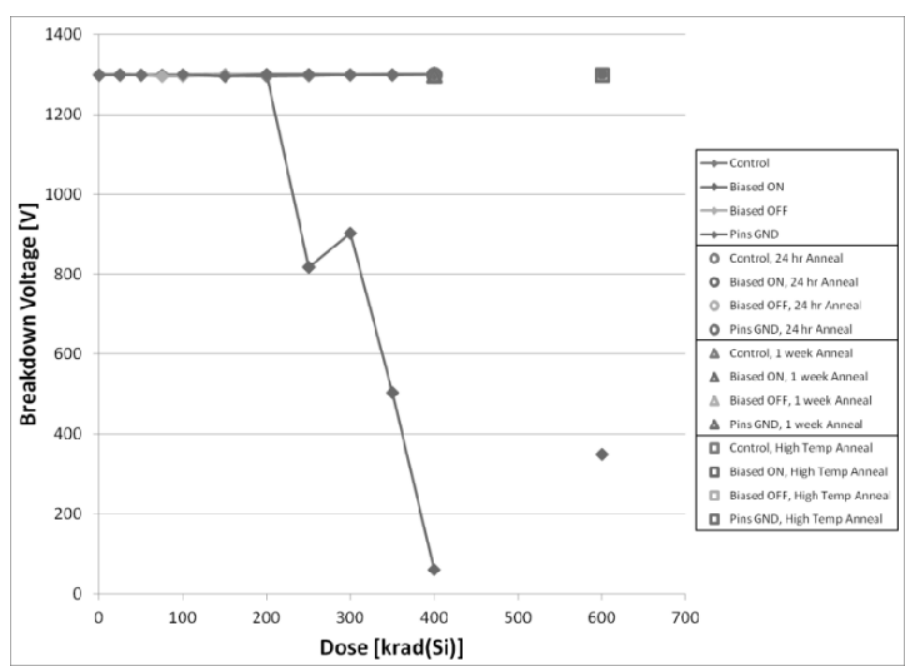

Fig. 2. The average breakdown voltage for the CMF20120D as a function of dose.

\section{B. M379T2863FB3-CF7/Samusung DDR2 Memory DIMM}

Samsung 1-Gbit DDR2 DIMMs (part \# MV-2V1G4 fabricated with M379T2863FB3-CF7 die) were evaluated for tolerance to TID degradation. The parts were irradiated according MIL-STD 883 Method 1019.8, with the exception that the dose rate was between 5 and $30 \mathrm{rad}(\mathrm{Si}) / \mathrm{s}$, rather than 50-300 $\mathrm{rad}(\mathrm{Si}) / \mathrm{s}$. As each DIMM included 8 DDR2 die, a single DIMM provides some measure of part-to-part variation. One DIMM was irradiated unbiased, while the other was irradiated with a static bias applied to VDD. The unbiased DIMM showed very little degradation in either DC parameters (IDD during operational conditions as defined in Table V) per the JEDEC DDR2 specification [4] or the timing parameters, but failed functionally at $900 \mathrm{krad}(\mathrm{Si})$. 
For both biased and unbiased DIMMs, the first dynamic test that failed was the Hammer Read, in which the tester reads repeatedly from the same memory address. This indicates that it is likely that the functional failures arise from weak cells in the memory and are unrelated to the behavior of the DC parameters shown in Table $\mathrm{V}$ and Fig. 3.

TABLE V

LIST OF OPERATIONAL CURRENTS

\begin{tabular}{|c|c|c|c|}
\hline Parameter & Description & Parameter & Description \\
\hline IDD0 & $\begin{array}{c}\text { Operating One } \\
\text { Bank Active- } \\
\text { Precharge }\end{array}$ & IDD3N & $\begin{array}{c}\text { Active } \\
\text { Standby }\end{array}$ \\
\hline IDD1 & $\begin{array}{c}\text { Operating One } \\
\text { Bank Active- } \\
\text { Read- } \\
\text { Precharge }\end{array}$ & IDD4R & $\begin{array}{c}\text { Operating } \\
\text { Burst Read }\end{array}$ \\
\hline IDD2P & $\begin{array}{c}\text { Precharge } \\
\text { Power-Down } \\
\text { (slow exit) }\end{array}$ & IDD4W & $\begin{array}{c}\text { Operating } \\
\text { Burst Write }\end{array}$ \\
\hline IDD2N & $\begin{array}{c}\text { Precharge } \\
\text { Standby }\end{array}$ & IDD5B & Burst Refresh \\
\hline IDD2Q & $\begin{array}{c}\text { Precharge } \\
\text { Quiet Standby }\end{array}$ & IDD6 & $\begin{array}{c}\text { Self Refresh } \\
\text { IDD3P }\end{array}$ \\
$\begin{array}{c}\text { Active Power- } \\
\text { Down } \\
\text { (fast exit) }\end{array}$ & IDD7 & $\begin{array}{c}\text { Operating } \\
\text { Bank } \\
\text { Interleave } \\
\text { Read }\end{array}$ \\
\hline
\end{tabular}

In contrast, parts irradiated with static bias showed more or less monotonic increase in current drawn, exceeding specified values at $\sim 150 \mathrm{krad}(\mathrm{Si})$ for IDD5B, the Burst Autorefresh Current. (See Fig. 3) Four other operational currents, first IDD3P ( 180 krad(Si)), then IDD3N and IDD4W (220 $\mathrm{krad}(\mathrm{Si}))$ and finally IDD4R ( 275 $\mathrm{krad}(\mathrm{Si}))$ also exceeded manufacturer's spec. Functional failure for the statically biased devices occurred at the $1 \operatorname{Mrad}(\mathrm{Si})$ dose step.

For both biased and unbiased DIMMs, the first dynamic test that failed was the Hammer Read, in which the tester reads repeatedly from the same memory address. This indicates that it is likely that the functional failures arise from weak cells in the memory and are unrelated to the behavior of the DC parameters shown in Fig. 3.

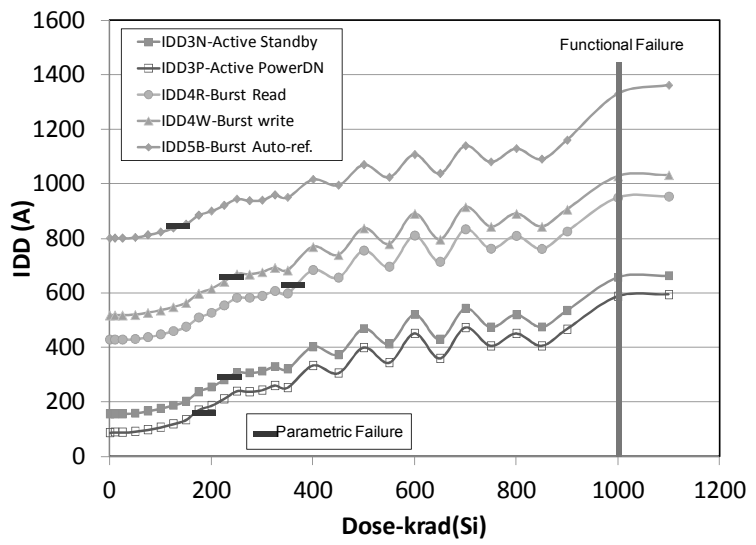

Fig. 3 Although statically biased Samsung DDR2 DIMMs exhibit monotonic degradation in operational supply currents, and 5 parameters exceed manufacturer's specification, functional failure occurred at roughly the same dose as for the unbiased DIMM.

\section{SUMMARY}

We have presented data from recent TID and protoninduced damage tests on a variety of primarily commercial devices. It is the authors' recommendation that this data be used with caution due to many application/lot-specific issues. We also highly recommend that lot testing be performed on any suspect or commercial device.

\section{AcKnowledgment}

The Authors would like to acknowledge the sponsors of this effort: NASA Electronic Parts and Packaging Program (NEPP), NASA Flight Projects, and the Defense Threat Reduction Agency (DTRA) under IACRO\# 11-4395I. The authors thank members of the Radiation Effects and Analysis Group (REAG) who contributed to the test results presented here: Steven K. Brown, Martin A. Carts, Stephen R. Cox, Anthony M. Dung-Phan, Mark Friendlich, James D. Forney, Donald K. Hawkins, Timothy L. Irwin, Hak S. Kim, Anthony B. Sanders, Christina M. Seidleck and Alyson D. Topper.

\section{REFERENCES}

[1] Martha V. O’Bryan, et al., "“Compendium of Single Event Effects for Candidate Spacecraft Electronics for NASA" by M. O'Bryan, et al." to be submitted for presentation at IEEE NSREC 2012 Radiation Effects Data Workshop, July 2012.

[2] Department of Defense "Test Method Standard Microcircuits," MIL-STD-883 Test Method 1019.8 Ionizing radiation (total dose) test procedure, September 30, 2010, http://www.dscc.dla.mil/Downloads/MilSpec/Docs/MIL-STD883/std883_1000.pdf. NASA/GSFC Radiation Effects and Analysis home page, http://radhome.gsfc.nasa.gov.

[3] NASA Electronic Parts and Packaging Program home page, http://nepp.nasa.gov.

[4] DDR2 SDRAM Specification JESD79-2F, JEDEC Solid State Technology Association, Arlington, VA, November 2009. 